\title{
Serum caspase-cleaved cytokeratin-18 fragment as a prognostic biomarker in hematological patients with febrile neutropenia
}

\author{
Carina Intke $^{1}$ (D) Sini Korpelainen ${ }^{2} \cdot$ Marika Lappalainen $^{1}$ (D) Matti Vänskä ${ }^{3,4}$ (D) Sari Hämäläinen ${ }^{1} \cdot$ Kari Pulkki $^{5,6}$ (D) \\ Esa Jantunen $^{1,2,7} \cdot$ Auni Juutilainen ${ }^{7}$ (D) Anna-Kaisa Purhonen ${ }^{8}$ (D)
}

Received: 19 April 2021 / Accepted: 21 June 2021 / Published online: 13 July 2021

(c) The Author(s) 2021

\begin{abstract}
The study aim was to determine the benefit of the measurement of serum caspase-cleaved cytokeratin-18 (CK-18) fragment as a prognostic marker of febrile neutropenia $(\mathrm{FN})$ in hematological patients. The study population consisted of 86 consecutive patients with FN who received intensive chemotherapy for hematological malignancy at the adult hematology ward of Kuopio University Hospital. Twenty-three patients (27\%) had acute myeloid leukemia, and 63 patients (73\%) were autologous stem cell transplant recipients. Serum caspase-cleaved CK-18 fragment M30, C-reactive protein (CRP) and procalcitonin (PCT) were measured at the onset of FN (d0), on day 1 (d1), and on day 2 (d2). Eight patients (9\%) developed severe sepsis, including three patients with septic shock. Eighteen patients (21\%) had a blood culture-positive infection. Serum CK-18 fragment peaked on the first day after fever onset in patients with severe sepsis. Higher CK-18 level was associated with severe sepsis, intensive care unit treatment, and fatal outcome, but not with blood culture positivity. In ROC curve analysis, d1 serum CK-18 fragment predicted severe sepsis with an area under the curve (AUC) of 0.767, CRP with an AUC of 0.764, and PCT with an AUC of 0.731. On d2, the best predictive capacity was observed for CRP with an AUC of 0.832. The optimal cutoff of caspase-cleaved CK-18 fragment M30 for predicting severe sepsis was $205 \mathrm{U} / \mathrm{L}$ on d1. In hematological patients, serum CK-18 fragment was found to be a potential prognostic marker of severe sepsis at early stages of FN.
\end{abstract}

Keywords Caspase-cleaved cytokeratin-18 $\cdot$ Febrile neutropenia $\cdot$ Severe sepsis $\cdot$ Acute myeloid leukemia $\cdot$ Non-Hodgkin lymphoma $\cdot$ Procalcitonin

Carina Intke

carina.intke@kuh.fi

Sini Korpelainen

sini.korpelainen@gmail.com

Marika Lappalainen

marika.lappalainen@kuh.fi

Matti Vänskä

matti.vanska@pshp.fi

Sari Hämäläinen

sari.hamalainen@kuh.fi

Kari Pulkki

kari.pulkki@hus.fi

Esa Jantunen

esa.jantunen@kuh.fi

Auni Juutilainen

auni.juutilainen@uef.fi

Anna-Kaisa Purhonen anna-kaisa.purhonen@eksote.fi
1 Department of Medicine, Institute of Clinical Medicine/ Internal Medicine, Kuopio University Hospital, P.O.B. 100, 70029 KYS Kuopio, Finland

2 Siun Sote - Hospital District of North Carelia, Joensuu, Finland

3 Department of Internal Medicine, Tampere University Hospital, Tampere, Finland

4 Department of Internal Medicine, Seinäjoki Central Hospital, Seinäjoki, Finland

5 Diagnostic Center, Helsinki University Hospital, Helsinki, Finland

6 Clinical Chemistry and Hematology, University of Helsinki, Helsinki, Finland

7 Institute of Clinical Medicine/Internal Medicine, University of Eastern Finland, Kuopio, Finland

8 Department of Internal Medicine, South Carelia Central Hospital, South Carelia Social and Health Care District (Eksote), Lappeenranta, Finland 


\section{Introduction}

Febrile neutropenia (FN) is a common complication in hematological patients receiving intensive chemotherapy for acute myeloid leukemia (AML) or autologous stem cell transplantation (ASCT). Outcome in patients with neutropenic sepsis may be fatal, so the diagnosis must be prompt and antimicrobial treatment adequate and timely.

Cytokeratins (CK) are structural proteins found in epithelial and parenchymal cells. They form the cytoplasmic network of intermediate filaments playing a role in apoptosis, mitosis, cell cycle progression, and cell signaling $[1,2]$. CK-18 has been investigated in several acute and chronic disease states [3-5], as well as in hepatology and histopathology [6-11]. In cancer research, it has been explored as a prognostic apoptosis-related marker [12]. CK-18 and its fragments are expected to correlate with tumor mass, tumor stage, and response to chemotherapy, as demonstrated in breast, colorectal, gastric, endometrial, lung, and prostate cancers among others [12-15].

Apoptosis is a form of programmed cell death, triggered by cysteine proteases of the caspase family. In apoptosis the dying cells are phagocytized before undergoing membrane damage, in contrast to other forms of programmed cell death [16]. Apoptosis is considered a vital component of various processes, including normal cell turnover, proper development and function of the immune system, hormone-dependent atrophy, embryonic development, and chemical-induced cell death [17]. Apoptosis is also a potential mechanism in sepsis and its complications [18, 19]. Several biomarkers for apoptosis have been recognized [20]. In apoptosis, intracellular CK-18 is cleaved by caspase- 3 at two sites and the released fragments can be measured from blood using antibody against exposed M30 neoepitope [1]. Later in the results section, we refer with "CK-18" to caspase-cleaved CK-18 fragment quantified by M30 epitope concentration.

Levels of CK-18 were reported to be higher in patients with sepsis than in trauma patients and healthy controls $[21,22]$. In critically ill patients with and without sepsis, the levels of CK-18 correlated with biomarkers of renal injury, liver injury, and high mortality [21, 22]. In patients with sepsis, high CK-18 levels have been observed to associate with mortality [23]. Also high caspase-3 levels have been found to be linked with early mortality of patients with severe sepsis [24].

CK-18 might be an especially interesting biomarker for hematological patients with FN as the intensive chemotherapy results both in cell death and mucosal injury. Furthermore, CK-18 is associated with organ failure in septic patients, an unfortunate consequence of FN. There are no previous studies on the use of caspase-cleaved CK-18 fragment levels as a prognostic marker in FN of hematological patients. The aim of this study is to evaluate the use of serum CK-18 fragment level as an early marker of severe complications of FN and to compare its performance with that of the conventionally used biomarkers C-reactive protein (CRP) and procalcitonin (PCT).

\section{Patients and methods}

\section{Patients}

The inclusion criteria were fulfilled if a patient had FN after intensive chemotherapy for AML or if the patient was an ASCT recipient. The study population consisted of $86 \mathrm{con}$ secutive patients with FN who received intensive chemotherapy for hematological malignancy between December 2009 and November 2012 at the adult hematology ward of Kuopio University Hospital. Twenty-three (27\%) patients had acute myeloid leukemia and 63 (73\%) patients were autologous stem cell transplant recipients (Table 1). None of the study participants had a diagnosed liver disease at the onset of the study. There were 55 males and 31 females with a median age of 61 years (18-70 years).

\section{Clinical follow-up}

All patients were carefully followed up at the hematology ward until recovery of neutropenia. Blood cultures (2-3 sets including 2 bottles/set) were drawn immediately at the beginning of FN. An additional sampling was done if fever persisted for more than three to five days. Blood pressure, oxygen saturation, respiratory frequency, heart rate, body temperature, urine output, fluid intake, as well as clinical signs of infection were followed up daily. Broad spectrum antibiotics were started after the samples for blood cultures were taken from cubital veins. The clinical data was recorded on a structured data collection form and included the hour and date of the start of fever, possible sites of infections, and hemodynamic parameters suggesting septic complications.

\section{Laboratory analyses}

Blood samples for CK-18 fragments, CRP and PCT were collected at the onset of FN (d0) and on the following next two mornings (d1 and d2). Serum was separated and samples stored frozen at $-70{ }^{\circ} \mathrm{C}$ until analysis. Blood cultures were processed using the automated blood culture system Bactec 9240 (Becton Dickinson, Sparks, MD, USA). The incubation time was 7 days for both aerobic and anaerobic bottles and 42 days for MYCO F/Lytic bottles. All samples 
Table 1 Baseline characteristics during febrile neutropenia in 86 hematological patients after intensive chemotherapy

\begin{tabular}{ll}
\hline Sex & \\
Male & $55(64 \%)$ \\
Female & $31(36 \%)$ \\
Age & \\
Median (min, max), years & $61(18-70)$ \\
$>$ 60 years & $46(53 \%)$ \\
Acute myeloid leukemia & $23(27 \%)$ \\
Autologous stem cell transplantation & $63(73 \%)$ \\
Non-Hodgkin lymphoma & $43(50 \%)$ \\
Multiple myeloma & $17(20 \%)$ \\
Hodgkin lymphoma & $3(3.5 \%)$ \\
Chemotherapy regimen & \\
BEAM & $42(49 \%)$ \\
HD-MEL & $18(20 \%)$ \\
IdAraC-Ida & $9(10 \%)$ \\
IAT & $7(8.1 \%)$ \\
MEA & $4(4.7 \%)$ \\
Carmustine-Thiotepa & $3(3.5 \%)$ \\
Mito-HDAraC & $2(2.3 \%)$ \\
HDAraC-Ida & $1(1.2 \%)$ \\
Positive blood culture & $18(21 \%)$ \\
Gram-positive & $14(16.3 \%)$ \\
Gram-negative & $3(3.5 \%)$ \\
Fungal sepsis & $1(1.2 \%)$ \\
Severe sepsis & $8(9.3 \%)$ \\
Intensive care unit admission & $3(3.5 \%)$ \\
Death & $6(7.0 \%)$ \\
\hline & $3(3.5 \%)$ \\
\hline
\end{tabular}

$B E A M$, carmustine, etoposide, cytarabine, and melphalan; $H D-M E L$, high-dose melphalan; IAT, idarubicin, cytarabine, and thioguanine; IdAraC-Ida, intermediate-dose cytarabine and idarubicin; HDAraCIda, high-dose cytarabine and idarubicin; Mito-HDAraC, mitoxantrone and high-dose cytarabin; $M E A$, mitoxantrone, etoposide, and cytarabine

were analyzed at the Eastern Finland Laboratory Centre in random order and blinded with respect to clinical data (except for real-time measurement of CRP).

Measurement of caspase-cleaved CK-18 concentration was performed with M30 Apoptosense ${ }^{\circledR}$ CK18 Kit (VLVBio, Nacka, Sweden). As declared by the manufacturer, the range of concentration of CK-18 was $40-1000$ $\mathrm{U} / \mathrm{L}$, sensitivity $20 \mathrm{U} / \mathrm{L}$, within-assay variation $\leq 10 \%$, between-assay variation $\leq 10 \%$, and total variation $\leq 10 \%$ for samples with concentrations over 200 U/L. . The cutoff given by the manufacturer was $<200 \mathrm{U} / \mathrm{L}$ in normal subjects and the 95th percentile was $251 \mathrm{U} / \mathrm{L}$. According to the measurements in our laboratory, the intra-assay coefficient of variation $(\mathrm{CV})$ was $7.7 \%$ at $164 \mathrm{U} / \mathrm{L}$ and the inter-assay CVs were $4.0 \%$ at $128 \mathrm{U} / \mathrm{L}$ and $3.3 \%$ at 634 $\mathrm{U} / \mathrm{L}$, respectively.

The concentration of CRP was measured with a Konelab60i Clinical Chemistry Analyzer (Lab systems CLD, Konelab, Helsinki, Finland) or Cobas 6000-analyzer (Hitachi, Tokyo, Japan). The between-run variations ranged from 2.3 to $4.3 \%$. The upper reference limit of serum or plasma CRP of a healthy reference population is $5 \mathrm{mg} / \mathrm{L}$.

Plasma PCT was analyzed with Cobas 6000-analyzer (Hitachi, Tokyo, Japan). The sensitivity of the assay was $0.06 \mu \mathrm{g} / \mathrm{L}$. The within- and between-assay CVs for PCT analyses were 1.4 and $3.0 \%$ for $0.46 \mu \mathrm{g} / \mathrm{L}$ of PCT and 1.1 and $2.6 \%$ for $9.4 \mu \mathrm{g} / \mathrm{L}$ of PCT, respectively. The lower limit for PCT indicating a possible systemic infection is $0.5 \mu \mathrm{g} / \mathrm{L}$.

\section{Definitions}

Febrile neutropenia was defined using the criteria of the Infectious Diseases Society of America [25]. Neutropenia was considered as a condition of neutrophil count $<0.5 \times 10^{9} / \mathrm{L}$ or with a predicted decrease to $<0.5 \times 10^{9} / \mathrm{L}$ during the next $48 \mathrm{~h}$. Fever was defined as a single oral temperature of $38.3{ }^{\circ} \mathrm{C}$ or a temperature of $38.0^{\circ} \mathrm{C}$ sustained over a 1 -h period. Sepsis was defined as a syndrome, in which systemic inflammatory response was present with infection [26, 27]. Severe sepsis was defined as sepsis with organ dysfunction according to the definition enforced during the study, and septic shock was considered to be present if there was hypotension (systolic arterial pressure $<90 \mathrm{mmHg}$, mean arterial pressure $<60 \mathrm{mmHg}$, or a reduction in systolic blood pressure of $>40 \mathrm{mmHg}$ from baseline) despite adequate volume resuscitation in the absence of other causes of hypotension [28]. In February 2016, new definitions for sepsis and septic shock were announced [29], but in this prospective study design, we used the definitions that were available at the time of the study entry.

A single positive blood culture was considered significant if the microbe was a clinically relevant cause of infection. Common skin contaminants (e.g., coagulase-negative staphylococci) were considered significant only if they were found in two consecutive blood cultures or if there was a concurrent skin or catheter infection.

\section{Statistical analysis}

Data analyses were conducted with IBM SPSS Statistics 27 for Windows (IBM, Armonk, NY, USA). Categorical variables were given as absolute counts or frequencies. Because of the log-normal distribution of PCT, logarithmic transformation was used for other than nonparametric analyses of 
Table 2 Means and medians of cytokeratin-18, C-reactive protein and procalcitonin on day 0-2 from the onset of febrile neutropenia in 86 hematological patients according to the presence of severe sepsis after intensive chemotherapy

\begin{tabular}{|c|c|c|c|c|c|}
\hline & \multicolumn{2}{|c|}{ No severe sepsis $(N=78)$} & \multicolumn{2}{|c|}{ Severe sepsis $(N=8)$} & \multirow[t]{2}{*}{$P$ value ${ }^{\mathrm{a}}$} \\
\hline & Mean \pm SEM & Median (min, $\max )$ & Mean (SEM) & Median (min, $\max )$ & \\
\hline \multicolumn{6}{|c|}{ Cytokeratin-18 U/L } \\
\hline Day 0 & $186 \pm 11$ & $168(46,669)$ & $210 \pm 37$ & $180(113,456)$ & 0.326 \\
\hline Day 1 & $208 \pm 12$ & $179(75,566)$ & $367 \pm 77$ & $309(109,697)$ & $0.014^{*}$ \\
\hline Day 2 & $205 \pm 11$ & $188(56,722)$ & $315 \pm 55$ & $337(128,461)$ & 0.067 \\
\hline \multicolumn{6}{|c|}{$\begin{array}{l}C \text {-reactive } \\
\text { protein } \\
m g / L\end{array}$} \\
\hline Day 0 & $52 \pm 6$ & $36(5,286)$ & $71 \pm 22$ & $64(5,212)$ & 0.246 \\
\hline Day 1 & $88 \pm 9$ & $70(9,357)$ & $162 \pm 33$ & $143(48,327)$ & $0.015^{*}$ \\
\hline Day 2 & $114 \pm 10$ & $87(7,342)$ & $245 \pm 39$ & $231(129,367)$ & $0.004 * *$ \\
\hline \multicolumn{6}{|c|}{ Procalcitonin $\mu g / L$} \\
\hline Day 0 & $0.197 \pm 0.026$ & $0.128(0.037,1.74)$ & $3.793 \pm 3.547$ & $0.214(0.058,28.62)$ & 0.104 \\
\hline Day 1 & $0.856 \pm 0.406$ & $0.180(0.029,28.87)$ & $6.041 \pm 4.997$ & $0.981(0.075,40.92)$ & $0.032 *$ \\
\hline Day 2 & $0.776 \pm 0.296$ & $0.190(0.036,21.11)$ & $5.655 \pm 3.657$ & $1.440(0.073,26.90)$ & 0.057 \\
\hline
\end{tabular}

${ }^{*} P<0.05 ; * * P<0.01 ; * * * P<0.001$; ${ }^{\text {N}}$ Nonparametric Mann-Whitney U-test
PCT. Correlations between continuous variables were analyzed by the Spearman's correlation test. CK-18, PCT and CRP were reported as medians with ranges and means with standard errors of mean according to the presence of complications of FN. The nonparametric Mann-Whitney U-test used to evaluate the differences of continuous variables between two groups and Kruskal-Wallis test between more than two groups. Receiver operating characteristics curve (ROC) analysis was carried out to evaluate the prognostic value of CK-18, PCT and CRP, providing values for the area under the curve (AUC) with $95 \%$ confidence intervals (CI). The significance of differences between AUC values was tested by the method described by Hanley and McNeil [30]. Youden's indices (sensitivity + specificity-1) were calculated. Also weighted Youden's indices were used for determining alternative cutoffs [31]. The weighted Youden's index $\left(\mathrm{J}_{\mathrm{w}}\right)$ was defined as follows:

$$
\begin{aligned}
J_{w}= & 2 \times(\lambda \times \text { sensitivity }+(1-\lambda) \times \text { specificity }) \\
& -1 ;(0 \leq \lambda \leq 1)
\end{aligned}
$$

By definition, as the sum of the weights $(\lambda$ and $1-\lambda)$ is 1 , $\mathrm{J}_{\mathrm{w}}$ ranges from -1 to +1 (as also does unweighted Youden's index), and is equal to unweighted Youden's index when sensitivity and specificity have equal weights. The values $\lambda=2 / 3$ and $\lambda=1 / 3$ were used to emphasize sensitivity and specificity, respectively. A P value of less than 0.05 was considered significant.

\section{Ethical approval}

Informed consent was obtained from all individual participants included in the study. This study was conducted according to the principles expressed in the Declaration of
Helsinki and approved by the Ethical Board of North Savo Hospital District (100/2006).

\section{Results}

Eight patients developed severe sepsis (9.3\%) and six patients $(7.0 \%)$ were treated at intensive care unit (ICU). Three patients developed septic shock and two of them died (Table 1). One patient without septic shock died during induction therapy for AML. Six out of eight patients with severe sepsis had positive blood culture findings. Altogether $18 / 86$ patients $(21 \%)$ had a positive blood culture finding. Three patients had Gram-negative bacteremia, fourteen patients had Gram-positive bacteremia, and one patient had candidemia. Blood culture positivity was not associated with plasma CK-18 level on d0-d2, but CRP level on d1-d2 and PCT level on d1 was significantly higher in blood culture positive than in blood culture negative patients (data not shown).

In patients with severe sepsis, the levels of CK-18 and PCT on $\mathrm{d} 1$, and the level of CRP both on $\mathrm{d} 1$ and $\mathrm{d} 2$, were higher than in patients without severe sepsis (Table 2). The level of CK-18 peaked on $\mathrm{d} 1-\mathrm{d} 2$ in patients with severe sepsis (Fig. 1, Table 2). On d0 the levels of CK-18, CRP and PCT were similar in patients with and without severe sepsis.

In patients who developed septic shock, the level of CK-18 was higher on d1-d2 than in patients who did not develop septic shock (Fig. 1), with median (range) values of CK-18 185 (169-456) U/L on d0, 677 (251-697) U/L on $\mathrm{d} 1$, and 454 (448-461) U/L on $\mathrm{d} 2$. The maximum $\mathrm{d} 0-\mathrm{d} 2$ levels of CK-18, CRP and PCT differed between the patients 


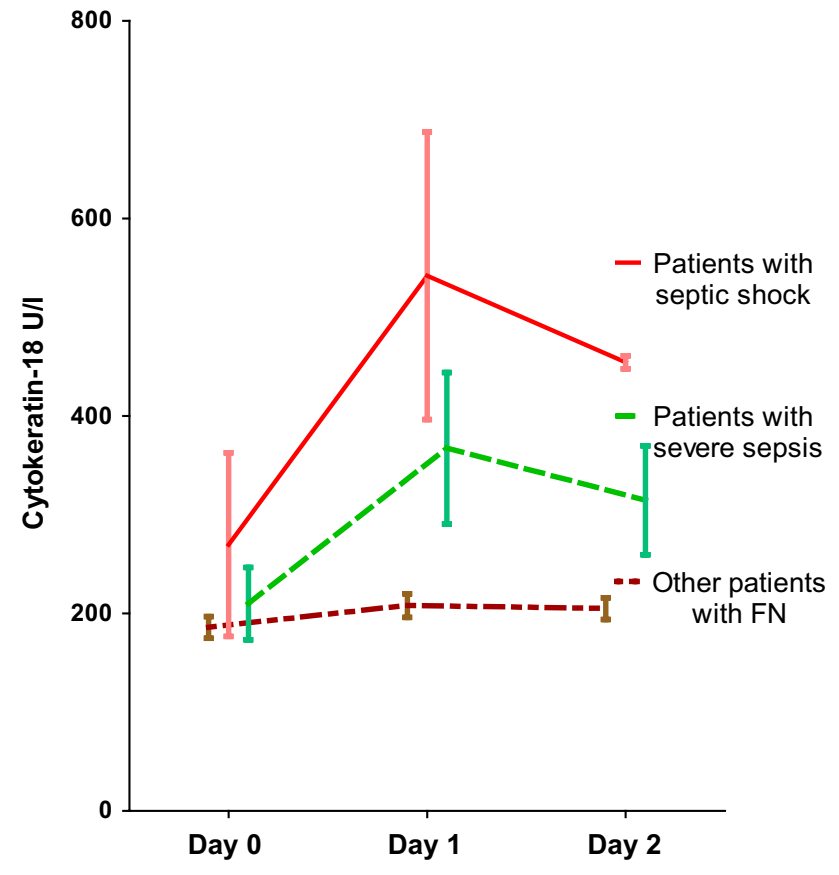

Fig. 1 Levels of cytokeratin-18 (M30) (mean with standard error of mean) from day 0 to day 2 according to septic complications in 86 patients with febrile neutropenia

with and without septic shock $(P$ values $0.001,0.008$ and 0.003 , respectively). CK-18, CRP and PCT also differed between patients with and without a need for ICU treatment ( $P$ values $0.024,0.005$ and 0.012 , respectively). Moreover, CK-18 and CRP differed between patients with and without fatal outcome during the hospital stay $(P$ values 0.015 and 0.024 , respectively), but the level of PCT was similar in these patient groups.
The biomarker levels were also evaluated according to the background malignancy. Higher serum levels of CK-18 were observed in patients with NHL than in patients with AML (Table 3). In contrast, the levels of CRP and PCT were similar in these two patient groups. Furthermore, the correlation of CK-18 with alanine aminotransferase, alkaline phosphatase, bilirubin, and body mass index was evaluated. No significant correlations were observed.

The results of the ROC curve analyses evaluating CK-18, CRP and PCT as predictors of severe sepsis are reported in Table 4 and Fig. 2. The AUCs on d1 after fever onset were highest for CK-18 $(0.767, P=0.011)$ and CRP $(0.764$, $P=0.001)$. On $\mathrm{d} 2$, only CRP showed a statistically significant AUC. Within maximum d0-d2 values, CRP showed the best performance with AUC $0.841(P<0.001)$, while the AUCs for CK-18 and PCT were $0.766(P=0.011)$ and 0.743 $(P=0.032)$, respectively. The differences between the AUCs were not statistically significant.

The diagnostic performance of CK-18, CRP and PCT from $\mathrm{d} 0-\mathrm{d} 2$ in FN is compared in Table 5. As sensitivity might be of special importance in search for cutoffs in this patient group at high risk for septic complications, also weighted Youden's indices are reported. At the same level of sensitivity of 0.88 on d1, CK-18 showed the highest Youden's index of 0.54 , in comparison to those of CRP (0.49) and PCT (0.31). When the cut-offs based on optimized unweighted Youden's index were used, PCT showed higher specificity but a lower sensitivity than CK-18 or CRP on d1. Weighting sensitivity had a disadvantageous effect (reduction of diagnostic odds ratio and Youden's index) on the performance of CK-18 on $\mathrm{d} 2$ and PCT on $\mathrm{d} 1$ and $\mathrm{d} 2$. Of note, on day 1 the diagnostic odds ratio was above the level of ten for CK-18 both by sensitivity and specificity weighted cutoffs, but only by sensitivity weighted cutoff for CRP and specificity weighted cutoff for PCT.
Table 3 Means and medians of cytokeratin-18, C-reactive protein and procalcitonin on day $0-2$ from the onset of febrile neutropenia in 66 patients according to the diagnosis acute myeloid leukemia (AML) vs. non-Hodgkin lymphoma (NHL)

\begin{tabular}{|c|c|c|c|c|c|}
\hline & \multicolumn{2}{|c|}{ Patients with AML $(N=23)$} & \multicolumn{2}{|c|}{ Patients with NHL $(N=43)$} & \multirow[t]{2}{*}{$P$ value* } \\
\hline & Mean \pm SEM & Median (min, $\max$ ) & Mean (SEM) & Median (min, max) & \\
\hline \multicolumn{6}{|c|}{ Cytokeratin-18 U/L } \\
\hline Day 0 & $179 \pm 29$ & $132(46,669)$ & $203 \pm 13$ & $181(98,456)$ & $0.015^{*}$ \\
\hline Day 1 & $212 \pm 35$ & $141(75,677)$ & $245 \pm 19$ & $203(112,697)$ & $0.008 * *$ \\
\hline Day 2 & $187 \pm 29$ & $187(56,722)$ & $243 \pm 16$ & $210(129,492)$ & $0.003 * *$ \\
\hline \multicolumn{6}{|c|}{$C$-reactive protein $\mathrm{mg} / \mathrm{L}$} \\
\hline Day 0 & $78 \pm 17$ & $52(6286)$ & $50 \pm 6$ & $39(5,151)$ & 0.562 \\
\hline Day 1 & $118 \pm 20$ & $89(14,347)$ & $109 \pm 12$ & $90(25,357)$ & 0.908 \\
\hline Day 2 & $129 \pm 16$ & $121(7,273)$ & $157 \pm 16$ & $151(20,367)$ & 0.398 \\
\hline \multicolumn{6}{|c|}{ Procalcitonin $\mu g / L$} \\
\hline Day 0 & $1.511 \pm 1.235$ & $0.137(0.054,28.62)$ & $0.201 \pm 0.022$ & $0.157(0.038,0.678)$ & 0.800 \\
\hline Day 1 & $4.000 \pm 2.129$ & $0.254(0.075,40.92)$ & $0.444 \pm 0.094$ & $0.212(0.039,3.270)$ & 0.607 \\
\hline Day 2 & $1.693 \pm 0.986$ & $0.234(0.063,21.11)$ & $1.396 \pm 0.660$ & $0.277(0.036,26.90)$ & 0.927 \\
\hline
\end{tabular}


Table 4 ROC curve analysis of cytokeratin-18, C-reactive protein and procalcitonin on day $0-2$ from the start of febrile neutropenia in predicting severe sepsis in 86 hematological patients after intensive chemotherapy

Area under $95 \%$ confidence interval $P$ value the curve

\begin{tabular}{lccc}
\hline $\begin{array}{l}\text { Cytokeratin-18 } \\
\text { Day 0 }\end{array}$ & 0.606 & $0.428-0.783$ & 0.243 \\
Day 1 & 0.767 & $0.562-0.972$ & $0.011^{*}$ \\
Day 2 & 0.710 & $0.471-0.950$ & 0.086 \\
Max Day 0-2 & 0.766 & $0.562-0.970$ & $0.011^{*}$ \\
C-reactive protein & & \\
Day 0 & 0.626 & $0.427-0.825$ & 0.215 \\
Day 1 & 0.764 & $0.604-0.924$ & $0.001^{* *}$ \\
Day 2 & 0.832 & $0.701-0.963$ & $<0.001^{* * *}$ \\
Max Day 0-2 & 0.841 & $0.723-0.958$ & $<0.001^{* * *}$ \\
Procalcitonin & & & \\
Day 0 & 0.675 & $0.466-0.885$ & 0.101 \\
Day 1 & 0.731 & $0.516-0.946$ & $0.035^{*}$ \\
Day 2 & 0.718 & $0.477-0.959$ & 0.077 \\
Max Day 0-2 & 0.743 & $0.521-0.964$ & $0.032^{*}$ \\
\hline
\end{tabular}

${ }^{*} P<0.05 ; * * P<0.01 ; * * * P<0.001$

To explore the role of CK-18 among other markers in FN, we investigated the correlation between CK-18 and CRP, PCT, tissue inhibitor of metalloproteinase-1 (TIMP1), matrix metalloprotein-10 (MMP-10), and soluble CD14 subtype (sCD14), determined previously in the same patient population [32, 33]. The correlation of CK-18 fragment was highest with TIMP-1 $(r=0.431, P<0.001)$, followed by that with MMP-10 $(r=0.351, P=0.001)$, and PCT $(r=0.269$, $P=0.012$ ), while no significant correlation was observed with CRP or sCD14. Figure 3 shows the scatter plots for the relationships of cytokeratin-18 with CRP, PCT, MMP10, TIMP-1, and sCD14 in patients with severe sepsis and without severe sepsis. To further evaluate the association between CK-18 and PCT, the maximum d0-d2 CK-18 was plotted against the maximum $\mathrm{d} 0-\mathrm{d} 2$ logarithm-transformed PCT according to the development of severe sepsis (Fig. 4). The coefficient of determination $\left(R^{2}\right)$ was higher in patients developing severe sepsis (0.519) than in the rest of the patients (0.033).

\section{Discussion}

This is the first study on cytokeratin-18 fragment M30 as an apoptosis-related prognostic marker in febrile neutropenia of hematological patients. The main finding of the study was that the level of M30 antibody detected fragments of CK-18 was higher on the first days of $\mathrm{FN}$ in patients who
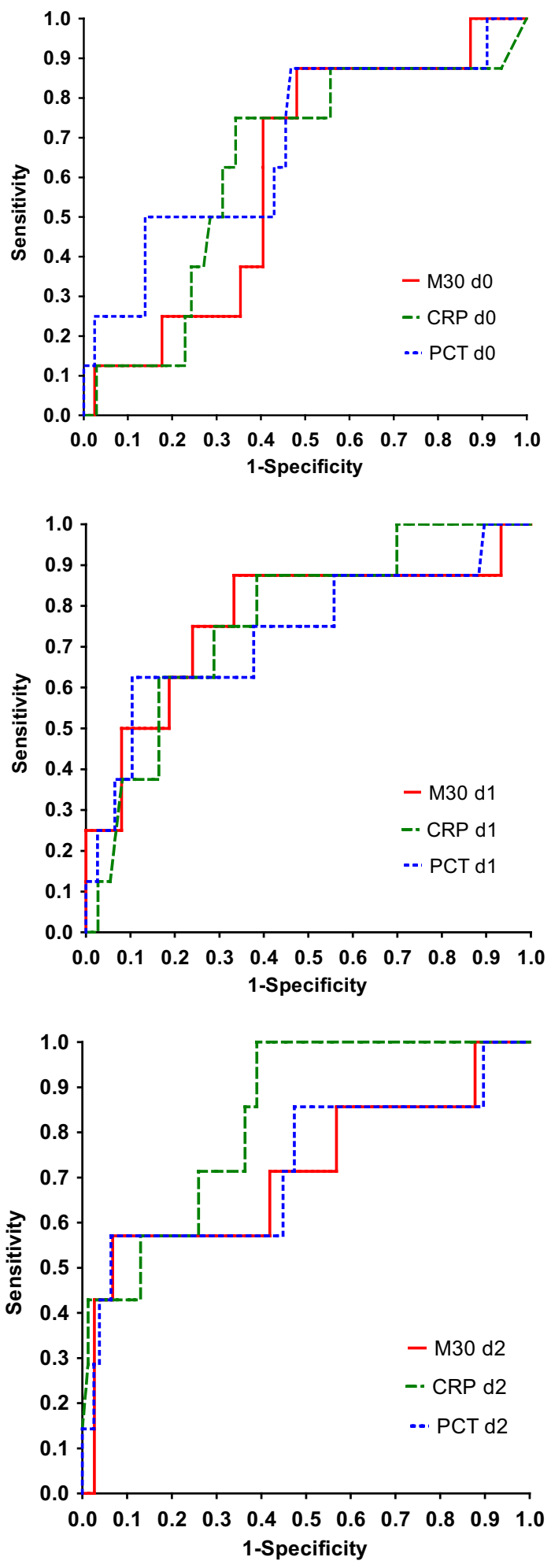

Fig. 2 ROC curve analysis of cytokeratin-18 (M30). C-reactive protein (CRP) and procalcitonin (PCT) measured on day 0 (top), day 1 (middle), or day 2 (bottom) from the start of febrile neutropenia as a predictor of severe sepsis in 86 hematological patients after intensive chemotherapy 
Table 5 Diagnostic performance of serum cytokeratin-18 (CK-18), C-reactive protein (CRP) and procalcitonin (PCT) in predicting the development of severe sepsis after intensive chemotherapy on day 0 , day 1 , and day 2 after the onset of febrile neutropenia in 86 hematological patients. The alternative cut-offs are based on weighted Youden's indices $\left(\mathrm{J}_{\mathrm{w}}\right)$ (more sensitive: $\lambda=2 / 3$; less sensitive: $\lambda=1 / 3$ )

\begin{tabular}{|c|c|c|c|c|c|c|}
\hline & \multicolumn{2}{|l|}{ CK-18 } & \multicolumn{2}{|l|}{ CRP } & \multicolumn{2}{|l|}{ PCT } \\
\hline & $\lambda=2 / 3$ & $\lambda=1 / 3$ & $\lambda=2 / 3$ & $\lambda=1 / 3$ & $\lambda=2 / 3$ & $\lambda=1 / 3$ \\
\hline \multicolumn{7}{|l|}{ Day 0} \\
\hline Cut-off & $169 \mathrm{U} / \mathrm{L}^{*}$ & $448 U / L$ & $51 \mathrm{mg} / \mathrm{L}^{*}$ & $182 \mathrm{mg} / \mathrm{L}$ & $0.138 \mu \mathrm{g} / \mathrm{L}^{*}$ & $0.273 \mu \mathrm{g} / L$ \\
\hline Sensitivity & 0.88 & 0.13 & 0.75 & 0.13 & 0.88 & 0.50 \\
\hline Specificity & 0.51 & 0.97 & 0.65 & 0.97 & 0.53 & 0.86 \\
\hline $\mathrm{LR}+$ & 1.80 & 4.88 & 2.16 & 4.31 & 1.84 & 3.55 \\
\hline LR- & 0.24 & 0.90 & 0.38 & 0.90 & 0.24 & 0.58 \\
\hline DOR & 7.37 & 5.43 & 5.63 & 4.79 & 7.76 & 6.09 \\
\hline Youden & 0.39 & 0.10 & 0.40 & 0.10 & 0.40 & 0.36 \\
\hline $\mathrm{J}_{\mathrm{w}}$ & 0.51 & 0.38 & 0.44 & 0.38 & 0.52 & 0.48 \\
\hline \multicolumn{7}{|l|}{ Day 1} \\
\hline Cut-off & $205 \mathrm{U} / \mathrm{L}^{*}$ & $347 \mathrm{U} / \mathrm{L}$ & $86 \mathrm{mg} / \mathrm{L}^{*}$ & $133 \mathrm{mg} / \mathrm{L}$ & $0.154 \mu g / L$ & $0.887 \mu g / L^{*}$ \\
\hline Sensitivity & 0.88 & 0.50 & 0.88 & 0.63 & 0.88 & 0.63 \\
\hline Specificity & 0.66 & 0.92 & 0.61 & 0.83 & 0.43 & 0.89 \\
\hline $\mathrm{LR}+$ & 2.59 & 6.17 & 2.25 & 3.75 & 1.55 & 5.94 \\
\hline LR- & 0.19 & 0.54 & 0.20 & 0.45 & 0.29 & 0.42 \\
\hline DOR & 13.7 & 11.3 & 11.0 & 8.33 & 5.37 & 14.2 \\
\hline Youden & 0.54 & 0.42 & 0.49 & 0.46 & 0.31 & 0.52 \\
\hline $\mathrm{J}_{\mathrm{w}}$ & 0.61 & 0.56 & 0.57 & 0.53 & 0.46 & 0.61 \\
\hline \multicolumn{7}{|l|}{ Day 2} \\
\hline Cut-off & $176 \mathrm{U} / \mathrm{L}$ & $335 U / L^{*}$ & $126 \mathrm{mg} / \mathrm{L}^{*}$ & $334 \mathrm{mg} / \mathrm{L}$ & $0.204 \mu g / L$ & $1.280 \mu \mathrm{g} / \mathrm{L}^{*}$ \\
\hline Sensitivity & 0.86 & 0.57 & 1.00 & 0.43 & 0.86 & 0.57 \\
\hline Specificity & 0.42 & 0.93 & 0.61 & 0.99 & 0.52 & 0.94 \\
\hline $\mathrm{LR}+$ & 1.49 & 8.34 & 2.53 & 32.6 & 1.78 & 8.80 \\
\hline LR- & 0.34 & 0.46 & 0.00 & 0.58 & 0.28 & 0.46 \\
\hline DOR & 4.43 & 18.1 & $2.53 / 0^{\mathrm{a}}$ & 56.2 & 6.49 & 19.20 \\
\hline Youden & 0.28 & 0.50 & 0.61 & 0.42 & 0.38 & 0.51 \\
\hline $\mathrm{J}_{\mathrm{w}}$ & 0.43 & 0.62 & 0.74 & 0.60 & 0.49 & 0.63 \\
\hline
\end{tabular}

$P P V$, positive predictive value; $N P V$, negative predictive value; $L R+$, positive likelihood ratio; $L R$-, negative likelihood ratio; $D O R$, diagnostic odds ratio; "Same as the cutoff determined by the unweighted

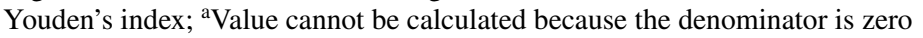

developed severe sepsis, septic shock or fatal outcome than in patients without these complications. On d1, which may be especially important from the clinician's viewpoint, the performance of CK-18 was comparable with but not superior to that of CRP and PCT, and on $\mathrm{d} 2$ only CRP was predictive. On $\mathrm{d} 0$, in this patient population, none of these three markers was predictive for the development of severe sepsis. Blood culture positivity did not affect the level of CK-18.

Apoptosis has an important role in eliminating infected or damaged cells. The hallmark of apoptosis is the activation of caspase- 3 protease which cleaves many different proteins including CK-18. Caspase- 3 mediated apoptosis is associated with lymphocyte apoptosis in sepsis and thus possibly also with the impairment of immune response [34, 35]. Although apoptosis is considered as a non-inflammatory process of programmed cell death, apoptotic cells may be subject to secondary necrosis in the absence of effective clearance, thus inducing some inflammatory response [36], and possibly a rise in both apoptotic and inflammatory biomarker levels.

Even though the association between liver disease and elevated CK-18 is evident $[4,8,9,37]$ there is no evidence that in our study, the causal relationship of our main finding would be linked to hepatic failure. However, organ failure of severe sepsis might be a theoretical linkage between the severity of sepsis and elevated CK-18 but unlikely to be the only one.

We found slightly higher d0-d2 CK-18 levels in FN of NHL than in AML patients but the levels of CRP and PCT were similar in these two patient groups. Previously we observed higher levels of cell-free DNA (cfDNA) in patients with NHL than in patients with AML [38]. Also cfDNA is recognized to reflect apoptosis. Of note, CK-18 is not expressed in cells of lymphoid origin, and thus it could be 


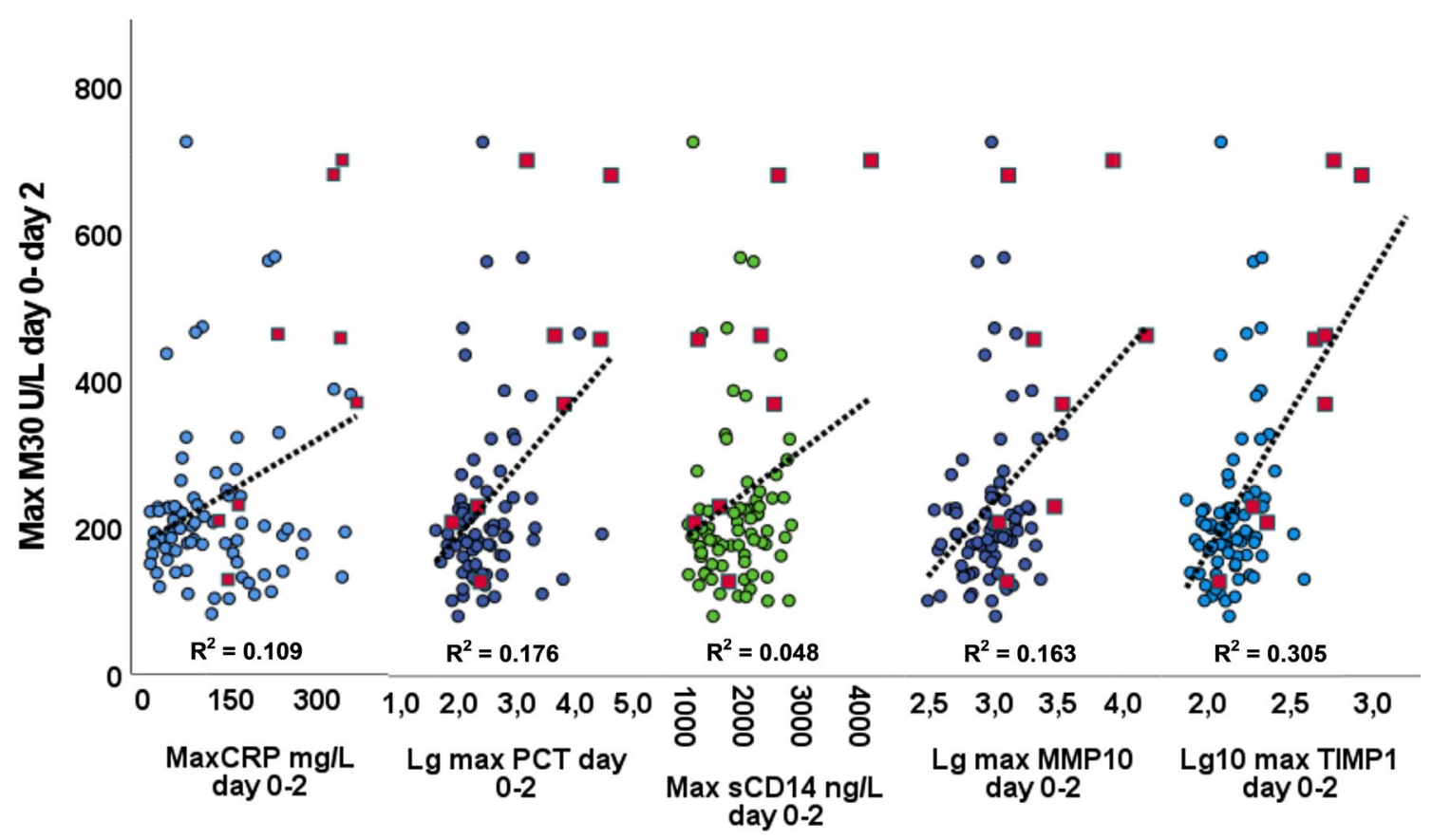

Fig. 3 Relationship of cytokeratin-18 fragment M30 neoepitope with C-reactive protein (CRP), procalcitonin (PCT), soluble CD14, matrix metalloproteinase-10 (MMP10), and tissue inhibitor of metallopro- teinase-1 (TIMP-1) in 86 hematological patients with severe sepsis (blue circles) or without severe sepsis (red squares). The coefficients of determination $\left(\mathrm{R}^{2}\right)$ and regression lines for each variable are given

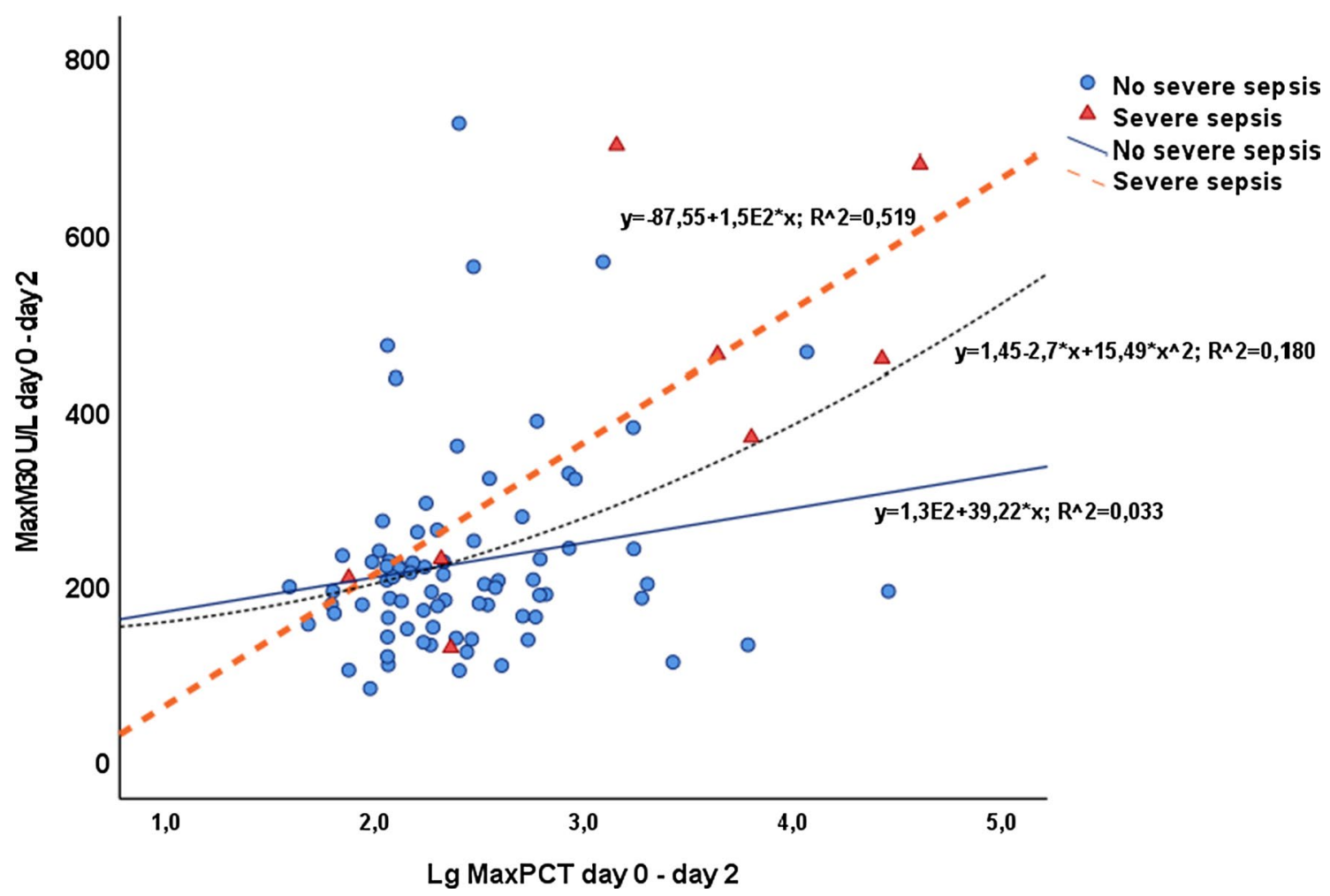

Fig. 4 Relationship between maximum cytokeratin-18 d0-d2 and maximum procalcitonin $\mathrm{d} 0-\mathrm{d} 2$ in 86 hematological patients. Coefficient of determination $\left(R^{2}\right)$ was higher in patients developing severe sepsis (0.519) than in patients not developing severe sepsis (0.033). The linear-quadratic fit $\left(R^{2}=0.180\right)$ is given for all patients 
used as a marker of treatment toxicity and gastrointestinal epithelial damage in lymphoma patients [39]. As previously observed, mucositis is found in a significant proportion of ASCT recipients at the time of FN [32]. In patients with lymphoma, Greystoke et al. observed an early difference in the CK-18 profiles between patients with and without clinical symptoms of toxicity, with the maximum level of CK-18 observed already on $\mathrm{d} 3$ while the clinical symptoms typically appeared on d7-d14 [39]. Thus, treatment toxicity-related epithelial damage is a plausible explanation for the difference in the CK-18 levels between AML and NHL patients observed in our study.

PCT is considered to have a better diagnostic capacity than CRP to predict complicated course of FN [40]. It also appears to be useful in distinguishing sepsis from noninfectious causes in FN [41]. In this study, the maximum d0-d2 CK-18 concentration correlated with PCT especially in patients with complicated FN. This finding is parallel to what was reported in a study with critically ill patients, where CK-18 level was associated with organ dysfunction, disease severity, and short-term mortality [22].

Meanwhile, the positive correlation between CK-18 and PCT was noted in our study of hematological patients with FN and in the study by Koch et al. including critically ill patients, no correlation between CK-18 and CRP was observed [22]. CRP is widely used to indicate infection, but it is a slow prognostic marker not peaking until $48-72 \mathrm{~h}$ after the onset of neutropenic fever [42]. As a future perspective, a combination of biomarkers with good diagnostic properties but without strong mutual correlation, thus reflecting different aspects of neutropenic infection, could be worth exploring.

There are some obvious limitations in this study. The main limitation of the study was the small number of FN patients with severe complications. In addition, we did not have the baseline CK-18 values from our patients before the start of intensive chemotherapy nor at the time of recovery from FN. The strengths of this study include the homogenous patient group consisting of neutropenic hematological patients with a recent history of intensive chemotherapy, early and well scheduled sampling, and prospective data collection for over 3 years. Of note, our FN study population had no previous liver diseases.

CK-18 is a potential early marker of severe complications in febrile neutropenia of hematological patients. Because of its role in apoptosis, it is of particular interest, complementing the spectrum of FN biomarkers. Further research is warranted to fully assess and understand the prognostic value of CK-18 in FN of hematological patients.

Acknowledgements The authors acknowledge Ms Raija Isomäki and Ms Anu Holopainen, MSc, for the technical assistance in the laboratory analyses, University of Eastern Finland including Kuopio University
Hospital for providing the Open Access possibility and North Savo Hospital District for research grant.

Author contributions All authors, but especially Esa Jantunen, Kari Pulkki, Sari Hämäläinen, and Auni Juutilainen contributed to the study conception and design. Data collection was performed by Sini Korpelainen, Matti Vänskä, Sari Hämäläinen, Anna-Kaisa Purhonen, Marika Lappalainen, and Esa Jantunen. Carina Intke and Auni Juutilainen analyzed and visualized the data. Carina Intke wrote the first draft of the manuscript. All authors commented, edited, and revised the manuscript, and read and approved the final version of the manuscript to be published.

Funding Open access funding provided by University of Eastern Finland (UEF) including Kuopio University Hospital. None.

Data availability The datasets generated during the current study are available from the corresponding author on reasonable request.

\section{Declarations}

Conflicts of interest The authors have no relevant financial or nonfinancial interests to disclose.

Ethical approval This study was performed in line with the principles of the Declaration of Helsinki. Approval was granted by the Ethical Board of North Savo Hospital District (100/2006), Finland.

Consent to participate Informed consent was obtained from all individual participants included in the study.

Open Access This article is licensed under a Creative Commons Attribution 4.0 International License, which permits use, sharing, adaptation, distribution and reproduction in any medium or format, as long as you give appropriate credit to the original author(s) and the source, provide a link to the Creative Commons licence, and indicate if changes were made. The images or other third party material in this article are included in the article's Creative Commons licence, unless indicated otherwise in a credit line to the material. If material is not included in the article's Creative Commons licence and your intended use is not permitted by statutory regulation or exceeds the permitted use, you will need to obtain permission directly from the copyright holder. To view a copy of this licence, visit http://creativecommons.org/licenses/by/4.0/.

\section{References}

1. Kramer G, Erdal H, Mertens HJ, et al. Differentiation between cell death modes using measurements of different soluble forms of extracellular cytokeratin 18. Cancer Res. 2004;64(5):1751-6. https://doi.org/10.1158/0008-5472.can-03-2455.

2. Wimmer K, Sachet M, Oehler R. Circulating biomarkers of cell death. Clin Chim Acta. 2020;500:87-97. https://doi.org/10.1016/j. cca.2019.10.003.

3. Vlachos S, Tsaroucha AK, Konstantoudakis G, et al. Serum profiles of M30, M65 and interleukin-17 compared with C-reactive protein in patients with mild and severe acute pancreatitis. $\mathbf{J}$ Hepatobiliary Pancreat Sci. 2014;21(12):911-8. https://doi.org/ 10.1002/jhbp. 162.

4. Chang YH, Lin HC, Hwu DW, Chang DM, Lin KC, Lee YJ. Elevated serum cytokeratin-18 concentration in patients with type 2 
diabetes mellitus and non-alcoholic fatty liver disease. Ann Clin Biochem. 2019;56(1):141-7. https://doi.org/10.1177/0004563218 796259.

5. Yang MC, Liu HK, Su YT, Tsai CC, Wu JR. Serum apoptotic marker M30 is positively correlated with early diastolic dysfunction in adolescent obesity. PLoS ONE. 2019;14(5): e0217429. https://doi.org/10.1371/journal.pone.0217429.

6. Atkinson SR, Grove JI, Liebig S, et al. In severe alcoholic hepatitis, serum keratin-18 fragments are diagnostic, prognostic, and theragnostic biomarkers. Am J Gastroenterol. 2020;115(11):185768. https://doi.org/10.14309/ajg.0000000000000912.

7. Chu PG, Weiss LM. Keratin expression in human tissues and neoplasms. Histopathology. 2002;40(5):403-39. https://doi.org/10. 1046/j.1365-2559.2002.01387.x.

8. Ku NO, Strnad P, Bantel H, Omary MB. Keratins: Biomarkers and modulators of apoptotic and necrotic cell death in the liver. Hepatology. 2016;64(3):966-76. https://doi.org/10.1002/hep.28493.

9. Oweira H, Sadeghi M, Volker D, et al. Serum caspase-cleaved cytokeratin (M30) indicates severity of liver dysfunction and predicts liver outcome. Ann Transplant. 2018;23:393-400. https:// doi.org/10.12659/AOT.908031.

10. Yilmaz B, Aktas B, Altinbas A, et al. The role of M30 in predicting the severity of liver fibrosis and inflammation in chronic hepatitis B patients. Hepat Mon. 2016;16(9): e35640. https://doi. org/10.5812/hepatmon.35640.

11. Vatsalya V, Cave MC, Kong M, et al. Keratin 18 is a diagnostic and prognostic factor for acute alcoholic hepatitis. Clin Gastroenterol Hepatol. 2020;18(9):2046-54. https://doi.org/10.1016/j.cgh. 2019.11.050.

12. Weng YR, Cui Y, Fang JY. Biological functions of cytokeratin 18 in cancer. Mol Cancer Res. 2012;10(4):485-93. https://doi.org/10. 1158/1541-7786.MCR-11-0222.

13. Elalfy H, Besheer T, Arafa MM, El-Hussiny MA, El Latif MA, Alsayed SAM. Caspase-cleaved cytokeratin 18 fragment M30 as a potential biomarker of macrovascular invasion in hepatocellular carcinoma. J Gastrointest Cancer. 2018;49(3):260-7. https://doi. org/10.1007/s12029-017-9937-6.

14. Nagel M, Schulz J, Maderer A, et al. Cytokeratin-18 fragments predict treatment response and overall survival in gastric cancer in a randomized controlled trial. Tumour Biol. 2018;40(3):1010428318764007. https://doi.org/10.1177/10104 28318764007.

15. Sirniö P, Väyrynen JP, Mutt SJ, et al. Systemic inflammation is associated with circulating cell death released keratin 18 fragments in colorectal cancer. Oncoimmunology. 2020;9(1):1783046. https://doi.org/10.1080/2162402X.2020.1783046.

16. Wallach D, Kang TB, Dillon CP, Green DR. Programmed necrosis in inflammation: toward identification of the effector molecules. Science. 2016;352(6281):aaf2154. https://doi.org/10.1126/scien ce.aaf2154.

17. Elmore S. Apoptosis: a review of programmed cell death. Toxicol Pathol. 2007;35(4):495-516. https://doi.org/10.1080/0192623070 1320337.

18. Girardot T, Rimmelé T, Venet F, Monneret G. Apoptosis-induced lymphopenia in sepsis and other severe injuries. Apoptosis. 2017;22(2):295-305. https://doi.org/10.1007/s10495-016-1325-3.

19. Hotchkiss RS, Tinsley KW, Karl IE. Role of apoptotic cell death in sepsis. Scand J Infect Dis. 2003;35(9):585-92. https://doi.org/ 10.1080/00365540310015692.

20. Ward TH, Cummings J, Dean E, et al. Biomarkers of apoptosis. Br J Cancer. 2008;99(6):841-6. https://doi.org/10.1038/sj.bjc. 6604519.

21. Roth GA, Krenn C, Brunner M, et al. Elevated serum levels of epithelial cell apoptosis-specific cytokeratin 18 neoepitope M30 in critically ill patients. Shock. 2004;22(3):218-20. https://doi. org/10.1097/01.shk.0000136098.49672.0e.
22. Koch A, Yagmur E, Linka J, et al. High circulating caspasecleaved keratin 18 fragments (M30) indicate short-term mortality in critically ill patients. Dis Markers. 2018;2018:8583121. https:// doi.org/10.1155/2018/8583121.

23. Lorente L, Martín MM, Pérez-Cejas A, et al. Higher serum caspase-cleaved cytokeratin-18 levels during the first week of sepsis diagnosis in non-survivor patients. Clin Chem Lab Med. 2017;55(10):1621-9. https://doi.org/10.1515/cclm-2016-1034.

24. Lorente L, Martín MM, Ferreres J, et al. Serum caspase 3 levels are associated with early mortality in severe septic patients. J Crit Care. 2016;34:103-6. https://doi.org/10.1016/j.jcrc.2016.04.008.

25. Hughes WT, Armstrong D, Bodey GP, et al. 2002 guidelines for the use of antimicrobial agents in neutropenic patients with cancer. Clin Infect Dis. 2002;34(6):730-51. https://doi.org/10.1086/ 339215.

26. Bone RC, Balk RA, Cerra FB, et al. Definitions for sepsis and organ failure and guidelines for the use of innovative therapies in sepsis The ACCP/SCCM Consensus Conference Committee American College of Chest Physicians/Society of Critical Care Medicine. Chest. 1992;101(6):1644-55. https://doi.org/10.1378/ chest.101.6.1644.

27. Levy MM, Fink MP, Marshall JC, et al. 2001 SCCM/ESICM/ ACCP/ATS/SIS international sepsis definitions conference. Crit Care Med. 2003;31(4):1250-6. https://doi.org/10.1097/01.CCM. 0000050454.01978.3B

28. Dellinger RP, Levy MM, Rhodes A, et al. Surviving Sepsis Campaign: international guidelines for management of severe sepsis and septic shock, 2012. Intensive Care Med. 2013;39(2):165-228. https://doi.org/10.1007/s00134-012-2769-8.

29. Singer M, Deutschman CS, Seymour CW, et al. The third international consensus definitions for sepsis and septic shock (Sepsis-3). JAMA. 2016;315(8):801-10. https://doi.org/10.1001/jama.2016. 0287.

30. Hanley JA, McNeil BJ. A method of comparing the areas under receiver operating characteristic curves derived from the same cases. Radiology. 1983;148(3):839-43. https://doi.org/10.1148/ radiology.148.3.6878708.

31. Li DL, Shen F, Yin Y, Peng JX, Chen PY. Weighted Youden index and its two-independent-sample comparison based on weighted sensitivity and specificity. Chin Med J (Engl). 2013;126(6):1150-4.

32. Becker S, Korpelainen S, Arvonen M, et al. MMP-10 and TIMP-1 as indicators of severe sepsis in adult hematological patients with febrile neutropenia. Leuk Lymphoma. 2019;60(12):3036-43. https://doi.org/10.1080/10428194.2019.1617859.

33. Korpelainen S, Intke C, Hämäläinen S, Jantunen E, Juutilainen A, Pulkki K. Soluble CD14 as a diagnostic and prognostic biomarker in hematological patients with febrile neutropenia. Dis Markers. 2017;2017:9805609. https://doi.org/10.1155/2017/9805609.

34. Cao C, Yu M, Chai Y. Pathological alteration and therapeutic implications of sepsis-induced immune cell apoptosis. Cell Death Dis. 2019;10(10):782. https://doi.org/10.1038/ s41419-019-2015-1.

35. Hotchkiss RS, Osmon SB, Chang KC, Wagner TH, Coopersmith CM, Karl IE. Accelerated lymphocyte death in sepsis occurs by both the death receptor and mitochondrial pathways. J Immunol. 2005;174(8):5110-8. https://doi.org/10.4049/jimmunol.174.8. 5110.

36. Kim EH, Wong SW, Martinez J. Programmed necrosis and disease: we interrupt your regular programming to bring you necroinflammation. Cell Death Differ. 2019;26(1):25-40. https://doi. org/10.1038/s41418-018-0179-3. 
37. Hofer S, Brenner T, Bopp C, et al. Cell death serum biomarkers are early predictors for survival in severe septic patients with hepatic dysfunction. Crit Care. 2009;13(3):R93. https://doi.org/ 10.1186/cc7923.

38. Purhonen AK, Juutilainen A, Vanska M, et al. Human plasma cell-free DNA as a predictor of infectious complications of neutropenic fever in hematological patients. Infect Dis (Lond). 2015;47(4):255-9. https://doi.org/10.3109/00365548.2014. 985711.

39. Greystoke A, O'Connor JP, Linton K, et al. Assessment of circulating biomarkers for potential pharmacodynamic utility in patients with lymphoma. Br J Cancer. 2011;104(4):719-25. https://doi.org/10.1038/sj.bjc.6606082.

40. Wu CW, Wu JY, Chen CK, et al. Does procalcitonin, C-reactive protein, or interleukin- 6 test have a role in the diagnosis of severe infection in patients with febrile neutropenia? A systematic review and meta-analysis. Support Care Cancer. 2015;23(10):2863-72. https://doi.org/10.1007/s00520-015-2650-8.

41. Sakr Y, Sponholz C, Tuche F, Brunkhorst F, Reinhart K. The role of procalcitonin in febrile neutropenic patients: review of the literature. Infection. 2008;36(5):396-407. https://doi.org/10.1007/ s15010-008-7374-y.

42. Manian FA. A prospective study of daily measurement of C-reactive protein in serum of adults with neutropenia. Clin Infect Dis. 1995;21(1):114-21. https://doi.org/10.1093/clinids/21.1.114.

Publisher's Note Springer Nature remains neutral with regard to jurisdictional claims in published maps and institutional affiliations. 